\title{
Degradation of rubber to metals bonds during its cathodic delamination, validation of an artificial ageing test
}

\author{
Maryline Nakache ${ }^{a}$, Emmanuel Aragon ${ }^{a}$, Lénaïk Belec $^{a},{ }^{,}$, François-Xavier Perrin ${ }^{a}$, Gérard Roux ${ }^{b}$, \\ Pierre-Yves Le Gac ${ }^{c}$
}

\author{
${ }^{a}$ Matériaux Polymère Interface Environnement Marin, MAPIEM, Université de Toulon et du Var, avenue Georges \\ Pompidou, 83160 La Valette du Var, France \\ b Thales Underwater Systems, TUS, route des Dolines, BP 157, 06903 Sophia-Antipolis Cedex, France \\ ${ }^{c}$ Materials and Structures Group, IFREMER (French Ocean Research Institute), Centre de Brest, BP 70, 29280 \\ Plouzané, France
}

*: Corresponding author : Lénaïk Belec, Tel.: +33 494142975 ; fax: +33 494142785

email address : belec@univ-tIn.fr

\begin{abstract}
:
Rubber-metal assemblies used for submarine applications are often associated to cathodic protection which can lead to cathodic disbonding of the polymer/metal interface.

The degradation mechanisms of polychloroprene/epoxy adhesive/copper-aluminium substrate systems associated to an accelerated ageing test are compared to the degradations resulting from natural ageing conditions in the Mediterranean sea. From destructives tests, a kinetic in four steps is identified for both ageing conditions. This kinetic is confirmed by Electrochemical Impedance Spectroscopy data during ageing. In order to further identify the failure mode, the disbonded surfaces on polymer and steel sides are analyzed using SEM and FTIR. Both ageing conditions present the same type of degradation which validates the fact that the accelerated ageing protocol reproduces the natural conditions. The chemical transformations in delaminated epoxy are very similar to the chemical transformation in epoxy coatings under high energy electron-beam irradiation. However, bidendate metal carboxylates rather than carboxylic acid chain ends are the main oxidation products due to the alkaline environment at the coating-metal interface. It was shown that the metal/polymer interface is not destroyed by an alkaline attack but by a strongly oxidative attack caused by the intermediates of the oxygen reduction.
\end{abstract}

\section{Highlights}

The cathodic delamination of rubber to metal systems is studied. An accelerated ageing protocol is validated. Both natural and artificial ageing conditions lead to an oxidative degradation at polymer/metal interface. Metal carboxylates resulting from the oxidative degradation are identified. - Different delamination steps are determined, notably by Electrochemical Impedance Spectroscopy.

Keywords : Ageing ; Rubber to metal systems ; Cathodic delamination ; FTIR 


\section{Introduction}

Adhesive systems for rubber-to-metal bonding are widely used in different industrial fields. In military applications, rubber is bonded to metal substrates in acoustic absorbers, sound reflectors and sonar transducers. These systems are associated with cathodic protection in order to prevent the corrosion of metallic structures immersed in seawater. Cathodic protection leads to the generation of a strong alkalinity at the metal/coating interface, which causes the delamination of the coating [1,2]. The mechanisms of cathodic delamination are usually classified into three groups. The first is the dissolution of the substrate oxide phase to which the polymer adheres [1-3]. This mechanism has been identified by ellipsometry used with $\mathrm{pH}$ probes under the film which indicates the very high alkalinity reached [4]. Nevertheless, oxide dissolution is widely criticized and depends on the nature of the substrate, the $\mathrm{pH}$ of the electrolyte and the potential applied, according to the Pourbaix diagrams. Castle and Watts [5] observe that the oxide is locally reduced, but the reduction is not a necessary precursor for cathodic delamination process.

The second mechanism is the degradation of the polymer/metal bonds at the interface $[6,7]$. The build-up of an alkaline environment may not be the only responsible for the loss of adhesion observed between the substrate and the coating. In fact, oxygen reduction produces many reaction intermediates, namely superoxides and hydroxyl radicals that lead to severe oxidation conditions [6,8-10]. The third mechanism proposed is the polymer degradation by alkaline hydrolysis $[3,11]$, sometimes referred to as saponification, or also by polymer oxidation due to intermediate species of oxygen reduction reaction [8,12]. Leng et al. [8] present some results on a polymer/steel system with a defect on the coating, aged in an sodium hydroxide electrolyte without oxygen. In that case, hydroxyl ions are present without oxidative species. They observe that the cathodic delamination rate is reduced.

The mechanisms of cathodic disbonding in the case of rubber to metal assemblies have not been widely studied yet. Stevenson [13] studies ageing of rubber vulcanized on steel and titanium. He reports that these systems are stable in electrochemically inert conditions. Moreover the type of rubber, the application of shear stresses, and the amount of water absorbed don't greatly affect the delamination rate. However, rapid failure of the bonds occurs when cathodic potentials are applied to steel. He confirms that hydroxyl ions resulting from oxygen reduction on steel surface are responsible for the rapid delamination but he doesn't precise the actual failure mechanisms. Boerio and Hong [14] study polychloroprene to steel adhesive bonds using FTIR and X-ray photoelectron spectroscopy. They find that methylene groups linking phenol moieties in the phenolic primer are rapidly attacked by hydroxyl ions, implying bonds failure. They also suggest that inorganic chlorides from polychloroprene are very soluble in water and may contribute to delamination by osmotic effects.

To simulate and accelerate the effects of coating damage in service, some accelerated life tests are proposed. Most of the accelerated life testing protocols that are developed for components under cathodic delamination in a marine environment are based upon the Arrhenius law using an increase in temperature or thermal cycles [15-18]. This approach suffers from two drawbacks. First, temperature may affect the physicochemical properties of the coating in terms of permittivity, strain, chemical bond rupture. Second, an increase of temperature leads to a decrease of oxygen solubility in sea water and, consequently, a decrease in delamination rate. Since cathodic delamination process is electrochemical in nature, the phenomenon can also be accelerated by applying a low cathodic potential on the substrate $[19,20]$, although excess negative potential might merely increase current draw and hydrogen production.

In this paper, the cathodic delamination mechanisms of a rubber to metal system, used for submarine application, is studied. The degradation mechanisms associated to an accelerating life test based on oxygen saturation in seawater are compared to the degradations resulting from natural ageing conditions in Mediterranean Sea. 


\section{Experimental}

\subsection{Materials}

The substrate is a copper-aluminium alloy used for its very good corrosion resistance in seawater, with 83 wt \% of $\mathrm{Cu}, 9 \mathrm{wt} \%$ of $\mathrm{Al}, 3.7 \mathrm{wt} \%$ of Ni, $2.8 \mathrm{wt} \%$ of iron and $1.2 \mathrm{wt} \%$ of manganese. The rubber is a polychloroprene with silica filler, sulphur vulcanized with $51 \mathrm{wt} \%$ of black carbon. Some artificial tests were also performed with a polyurethane elastomer based on 4,4'-Diphenylmethane Diisocyanate, MDI, and hydroxyl terminated polybutadiene. The thickness of the elastomer is 2 $\mathrm{mm}$. The adhesive used is a commercial epoxy based on the diglycidyl ether of bisphenol $A$ (DGEBA), cured with trioxatridecane diamine, with $5 \mathrm{wt} \%$ of silica.

\subsection{Samples preparation}

For the test at high $\mathrm{pH}$, epoxy adhesive films, with a thickness of $1 \mathrm{~mm}$ have been applied on a steel substrate covered with a release agent ant heated up to $50^{\circ} \mathrm{C}$ for $4 \mathrm{~h}$. The coating film is easily removed from the substrate after cure.

For assemblies, the substrate is cleaned in a hexafluoroethylene bath and sandblasted with corundum 120. The rubber, preliminarily abraded on one face, is stuck on the sandblasted substrate with the epoxy adhesive under a pressure of 2 bars. Then, the complete system is cured for $4 \mathrm{~h}$ at $50^{\circ} \mathrm{C}$. The epoxy adhesive thickness is about 20 micrometers. The samples are linearly scribed down to the substrate with an area of about $20 \mathrm{~mm}^{2}(20 \times 1 \mathrm{~mm})$.

\subsection{Ageing protocols}

For the test at high $\mathrm{pH}$, epoxy adhesive films and assemblies are immersed in a $1 \mathrm{M} \mathrm{NaOH}$ solution $(\mathrm{pH} 14)$ during two months. An electrolyte free of oxygen is provided by argon bubbling.

The experimental protocol used for artificial ageing is represented on Fig. 1. A plastic cell is stuck on the sample and filled with an artificial simplified sea water at ambient temperature $\left(18^{\circ} \mathrm{C}\right.$ to $22^{\circ} \mathrm{C}$ ), based on NSA $91-411$ with a pH of 8.2. This electrolyte is carbonates free in order to avoid scale deposit $\left(\mathrm{CaCO}_{3}\right.$ and $\left.\mathrm{Mg}(\mathrm{OH})_{2}\right)$. A three electrode system is used to apply a cathodic protection potential of $-0.8 \mathrm{~V}_{\text {ISCE }}$ which is in the oxygen reduction domain. Some destructive tests were also performed at $-1 \mathrm{~V}_{\text {ISCE }}$ to compare the influence of the cathodic potential on polymer degradation kinetics. A saturation of the electrolyte in oxygen is provided by oxygen bubbling with a concentration regulated between 18 and $20 \mathrm{mg} / \mathrm{L}$ using a flowmeter. Oxygen concentration is regularly measured by a calibrated oximeter Inolab Oxi Level2 during natural and artificial ageing.

For natural ageing, samples are immersed in seawater in Toulon during several months, at 1 meter depth and electrically connected to a sacrificial zinc anode. The potential measured on the substrate is $-1 \mathrm{~V}_{\text {/SCE }}$, the temperature of seawater is measured between 10 and $25^{\circ} \mathrm{C}$ with a mean $\mathrm{pH}$ of 8.2 and an oxygen concentration of $6 \mathrm{mg} / \mathrm{L}$.

\subsection{Characterisation}

Two different methods are used and compared to follow the evolution of delaminated areas during ageing time.

On one hand, destructive tests are performed by removing the elastomer from the substrate with a sharp knife. The borders between the disbonded and intact areas are distinct (Fig. 2). The surface 
of the disbonded area is determined using internal image calibrations digital imaging software. On the other hand, Electrochemical Impedance Spectroscopy enables non destructive measurements of the delaminated areas. The measurements are carried out on a 273A potenstiostat/galvanostat, coupled to an EG\&G Priceton Applied Research 1025 frequency analyzer. The tests are performed regularly during accelerated ageing, directly in the cell ageing. The dynamic potential is applied with a $10 \mathrm{mV}$ amplitude around $-0.8 \mathrm{~V}_{\text {/SCE }}$ to avoid sample corrosion, between $100 \mathrm{kHz}$ and 10 $\mathrm{mHz}$.

FTIR spectra are collected using a Nexus FTIR spectrophotometer with an Attenuated Total Reflectance (ATR) thunderdome accessory. All spectra were the coadditions of 32 scans taken at a resolution of $8 \mathrm{~cm}^{-1}$. The incident radiation's depth of penetration $d_{p}$ is defined as the distance required for the electric field amplitude to fall to $e^{-1}$ of its value at the surface and is given by [21]

$$
\mathrm{d}_{\mathrm{p}}=\frac{\lambda / n_{1}}{2 \pi\left(\sin ^{2} \theta-\left(\frac{n_{2}}{n_{1}}\right)^{2}\right)^{\frac{1}{2}}} \text { (eq.1) }
$$

where $\lambda=$ wavelength of the incident radiation, $\theta=$ incident angle of the radiation versus the line perpendicular to the surface of the sample $\left(45^{\circ}\right), \mathrm{n}_{1}=$ refractive index of the crystal $(\mathrm{Ge}=4.0)$ and $\mathrm{n}_{2}=$ refractive index of the analysed sample

The approximate depth of penetration was calculated to be $0.7 \mu \mathrm{m}$ at $1000 \mathrm{~cm}^{-1}$.

The surface of delaminated polymer and substrate are analysed by Scanning Electron Microscopy (SEM) using a Philips XL30 microscope under a voltage of $20 \mathrm{kV}$. The elementary analysis was performed with an Energy Dispersive X-ray Analysis (EDAX type). The organic specimens are metalized with gold before analysis.

\section{Results and discussion}

\subsection{Alkaline ageing}

The alkaline attack of polymer or polymer metal bonds is one of the mechanisms proposed by literature to explain cathodic delamination. To check alkaline resistance, epoxy films have been immersed in a $1 \mathrm{M} \mathrm{NaOH}$ solution $(\mathrm{pH} \mathrm{14})$ at ambient temperature during 2 months with argon bubbling to eliminate oxygen and consequently oxidative species. The sample, before and after ageing have been analyzed by FTIR spectroscopy. No evolution was observed, showing that the epoxy adhesive is very resistant to an alkaline environment. Moreover, no disbonding occurs for assemblies immersed in this electrolyte during 2 months, without cathodic protection. So we can conclude that the polymer/metal interface is resistant to an alkaline attack.

\subsection{Cathodic delamination kinetic}

Artificial and natural ageing of samples under cathodic protection have been conducted during 58 days and 6 months respectively. Photographs of sample for different immersion times and after manual peeling, showing the bonded and disbonded copper-aluminium surface, are presented on Fig. 3. The evolutions of the delaminated area as a function of time for both natural and artificial ageing are represented on Fig. 4 and Fig. 5 respectively. At least three specimens were tested for different immersion times and the percentage deviation was around $10 \%$. For both ageing, the same observations can be done: after a delay time, a radial delamination progress around the defect is observed. After several days of immersion (around 15 days for artificial ageing and 55 days for natural ageing), the disbonded area is directly proportional to the test duration. This linear kinetic could be attributed to an interfacial failure [22]. At longer immersion time, the progression of 
the delamination front appears to slow down. This stage was also observed by several authors on epoxy/steel systems [23,24]. This slow down can be attributed either to a potential gradient under the coating $[3,9]$. The accumulation of degraded species on delaminated areas can indeed create an ohmic drop. The last stage can also result from a lack of oxygen at the delamination front for large delaminated area due to the restrictive convective flow of the liquid or to the low oxygen permeability of the corrosion products [24].

Table 1 compares the four different stages in terms of duration and rate (stage III). The results show that the artificial test as defined in $\$ 2.3$ accelerates the ageing kinetics by a factor 4 compared to natural conditions. This acceleration can be associated to the difference in oxygen concentration in natural conditions (about $6 \mathrm{mg} / \mathrm{L}$ ) and in artificial ageing electrolyte $(19 \mathrm{mg} / \mathrm{L})$.

Delaminated areas were also followed by EIS measurements. A typical Nyquist plot of an aged sample is shown in Fig. 6. The impedance response for coatings containing an artificial defects is often modeled by a Randle circuit [25] containing the electrolyte resistance $R_{e}$, the charge transfer resistance $R_{c t}$, a double layer capacitance and a Warburg diffusive impedance $Z_{w}$. In our case, the small deviation of the high frequency semi-circle from $Z$ ' axis of Nyquist plot rather suggest the use of a constant phase element (CPE) instead of a pure capacitance as indicated in inset on Fig. 6 [26]. One can notice that CPE is very close to a pure capacitance $(n=0.9)$. The same circuit can be used for all ageing times. As shown on Fig. 5, the delamination kinetics followed by Electrochemical Impedance Spectroscopy are in good agreement with destructive data. $1 / R_{c t}$ values in the stage III are then proportional to the delaminated areas, as often mentioned in literature for thin coatings $[27,28]$. Above 50 days of accelerated ageing, $1 / R_{c t}$ values are almost constant. This is consistent with the slowdown of cathodic delamination attributed to the potential gradient $[3,9]$ or oxygen confinement under the coating [24].

In order to further identify the failure mode, the disbonded polymer and steel sides of samples are analyzed using SEM and FTIR.

\subsection{Characterization of the delaminated surface on substrate side}

Delaminated surfaces on the surface side have been observed for both ageing (Fig. 3). For sample artificially aged, different colors appears on substrates, attributed to different natures of oxides. This observation could be due to a potential gradient under the coating, from artificial defect to delamination front, and/or to a $\mathrm{pH}$ gradient [9]. For natural ageing, the potential imposed by anode is more negative (-1V/ECS) and could lead to different oxide formations.

Delaminated surfaces have been also investigated by SEM and EDX analysis. For both types of ageing, the same observations can be done: at the beginning of the delamination phenomenon, black stains are observed near the delamination front. When the ageing time increases, the delaminated surface appears clear and stains are mainly located beside the delamination front. Thus, these stains can be degraded after a longer contact with the electrolyte solution, under the coating. The delaminated surface of a sample artificially aged during 7 and 58 days is presented in Fig. 7 a) and b). An EDX primary analysis has been done on the "clear" surface without stain and on the stain. On the "clear" surface, only substrate elements can be detected: $\mathrm{Cu}, \mathrm{Al}, \mathrm{Fe}, \mathrm{Mn}$ and $\mathrm{Ni}$. EDX analysis in the stained areas (Fig. 6c) revealed the presence of $\mathrm{Si}$, from the adhesive and/or polychloroprene, and $\mathrm{S}$ and $\mathrm{K}$, from the polychloroprene. These stained areas are presumably regions of high adhesion.

\subsection{Characterization of the delaminated surface on polymer side}

EDX analyses have been performed on polymer side after artificial and natural ageing and are presented on Fig. 8. For artificial ageing (Fig. 8a), the surface analysis of the polymer shows silica element, which confirms that epoxy adhesive is present on rubber surface after delamination, $\mathrm{Cl}$ and $\mathrm{Na}$ coming from the electrolyte. Moreover, some elements from copper-aluminium substrate 
can be detected $(\mathrm{Cu}, \mathrm{Al})$. For natural ageing (Fig. 8b), the same observations can be done, except the presence of $\mathrm{Ca}, \mathrm{Mg}$ and $\mathrm{K}$ coming from scale deposit of natural seawater.

The presence of copper and aluminium elements could be a consequence of the dissolution of the oxides in the alkaline environment as aluminate $\left(\mathrm{AlO}_{2}{ }^{-}, \mathrm{Al}(\mathrm{OH})_{4}{ }^{-}\right)$and copper (II) species $\left(\mathrm{HCuO}_{2}{ }^{-}\right.$, $\mathrm{CuO}_{2}{ }^{2-}$ ). This dissolution of oxides could participate to the cathodic delamination phenomena [2] or just be a consequence of ageing [5]. $\mathrm{Cu}$ and $\mathrm{Al}$ can come from metal carboxylate complexes which have been identified by FTIR spectroscopy, as discussed below.

Fig. 9 shows the infrared spectra of the rubber and epoxy adhesive after curing but before degradation. The FTIR spectrum of rubber shows typical bands of polychloroprene filled with carbon black. The absorption bands at $1656 \mathrm{~cm}^{-1}$ and $1300 \mathrm{~cm}^{-1}$ are due to the $\mathrm{C}=\mathrm{C}$ stretching and $\mathrm{CH}$ in plane deformation of the $\mathrm{C}=\mathrm{C}$ group, respectively. The band at $1425 \mathrm{~cm}^{-1}$ is due to the $\mathrm{C}-\mathrm{H}$ deformation of $\mathrm{CH}_{2}$ groups. The rocking mode of $\mathrm{CH}_{2}$ group gives rise to the strong band at 820 $\mathrm{cm}^{-1}$ while the band around $1100 \mathrm{~cm}^{-1}$ is associated with C-C stretching vibration [29]. The FTIR spectrum of the epoxy adhesive shows bands characteristic of epoxy such as the $\mathrm{C}=\mathrm{C}$ bands at 1605,1512 and $1446 \mathrm{~cm}^{-1}$, the phenyl-oxygen stretching vibration at $1250 \mathrm{~cm}^{-1}$ and the aliphatic C$\mathrm{O}$ stretching vibration at $1035 \mathrm{~cm}^{-1}$. Fig. $9 \mathrm{~b}$ also displays FTIR spectrum of the delaminated surface obtained after 28 days exposure. Measurements were conducted at the center of the delaminated area. The IR spectrum of the delaminated surface exhibit the same pattern as the epoxy adhesive which proves that the failure location is near the epoxy-steel interface. IR spectra of the delaminated surface after 28,40 and 58 days of artificial ageing and after six months of natural ageing are shown in Fig. 10. The changes in IR spectra reveal a clear increase in the absorbance in the $1540-1590 \mathrm{~cm}^{-1}$ and $1340-1440 \mathrm{~cm}^{-1}$ region with the exposure time. The IR spectra of naturally aged samples present the same pattern as the artificially aged samples which suggest that the same degradation mechanisms occur in both ageing conditions. The two bands appearing around 1560 and $1420 \mathrm{~cm}^{-1}$ suggest the formation of carboxylates [30] due to oxidative attack by the superoxide and hydroxyl radicals that are formed as intermediates of the cathodic reduction of oxygen. For example, antisymmetric and symmetric vibrations of $\mathrm{C}-\mathrm{O}$ bonds are reported at 1591 and $1420 \mathrm{~cm}^{-1}$ for bidentate copper acetate, $\mathrm{Cu}_{2}\left(\mathrm{O}_{2} \mathrm{CCH}_{3}\right)_{4}$ and at 1560 and $1450 \mathrm{~cm}^{-1}$ for iron acetate, $\mathrm{Fe}_{4} \mathrm{O}\left(\mathrm{O}_{2} \mathrm{CCH}_{3}\right)_{10}[30,31]$. An important point to note is the fact that carboxylate products begins to be detected by FTIR spectroscopy after 28 days of artificial ageing (see Fig.10) while delamination is well advanced after 28 days of artificial ageing (see Fig.5). Therefore, the formation of the carboxylate degradation products is not the cause of the delamination. The kinetics of delamination and build-up of carboxylate species are thus not strictly related. From Fig.10, we can see that 6 months of natural ageing corresponds to a duration of between 28 and 40 days artificial ageing, in terms of carboxylate content.

To confirm this, we followed the peak intensity evolution at 1560 and $1415 \mathrm{~cm}^{-1}$ associated to the formation of carboxylate species during natural and artificial ageing (Fig. 11). The peak at $1510 \mathrm{~cm}^{-1}$ corresponding to the absorption of stable $\mathrm{C}=\mathrm{C}$ bonds of epoxy skeleton is chosen as reference. The relative peak intensities are then measured from a baseline taken between 1700 and $1330 \mathrm{~cm}^{-1}$. The reported values for each ageing time are mean values calculated on 3 spectra. The maximum deviation observed considering all ageing times is about \pm 0.1 and \pm 0.05 on relative peak intensity for $1560 \mathrm{~cm}^{-1}$ and $1415 \mathrm{~cm}^{-1}$ respectively.

The absorptions associated to carboxylate species increase progressively with time during both ageing conditions. This phenomena is accelerated by artificial ageing, by a factor 5 compared to the natural ageing which is then a little higher than the accelerating factor determined for the delamination process in the same conditions. In the cathodic delamination process, the oxygen reduction rate is conditioned by oxygen diffusion up to the working electrode, which increases with oxygen concentration. Then, an increase in oxygen concentration accelerates the polymer oxidative attack and the formation of carboxylate species.

Artificial delaminated tests have also been performed with a polyurethane/epoxy adhesive (copperaluminium) assembly. Most of the absorption bands in the FTIR spectrum correspond to the epoxy which shows that the location of delamination is near the epoxy-metal interface (Fig.12). We also 
observed an increase in the absorption intensities in the $1540-1590 \mathrm{~cm}^{-1}$ and $1340-1440 \mathrm{~cm}^{-1}$ region. The fact that the build-up of carboxylate products are observed both with polychloroprene/epoxy and polyurethane/epoxy assemblies confirm that these products result from epoxy degradation.

Fig. 13 compares the relative peak intensity at $1560 \mathrm{~cm}^{-1}$ measured at $-1 \mathrm{~V}_{\text {ISCE }}$ and $-0.8 \mathrm{~V}_{\text {ISCE }}$ during artificial ageing. The production of degradation species is clearly increased for a lower cathodic potential. It confirms that the epoxy degradation products directly depend on the oxidative species generated by the oxygen reduction reaction, whose rate depends on cathodic potential value.

In epoxide-amine networks, oxidative attack is highly selective and concerns the isopropanol group directly linked to tertiary nitrogen [32]. Phenyl formate end-groups are the main photoproduct formed when phenoxy resin films are exposed to radiation of long wavelengths $\lambda>300 \mathrm{~nm}$. The contribution of carboxylic acids is much higher for irradiation at short wavelength $(\lambda=254 \mathrm{~nm})$. Longieras et al. [33] recently studied the radio-oxidation of a DGEBA/TETA system irradiated under electron beam and observed that carboxylic acid chain ends were the main oxidation products. The reaction pathway involves the methylene groups in the $\alpha$ position to the ether group and the tertiary carbon atom substituted by the $\mathrm{OH}$ group (Fig. 14). In our specific conditions, oxygen reduction produces hydroxyl and superoxide intermediates leading to severe oxidation conditions. Chain scissions result in carboxylic acid chain ends as the main oxidation product by the same mechanism as that advanced by Gardette et al. [33]. The alkaline environment will produce carboxylates rather than carboxylic acids.

Three chemical structures of metal carboxylates are possible as shown in Fig. 15 : unidentate (a), bidentate chelating (b) and bidentate bridging (c). No absorption characteristics of $\mathrm{C}=\mathrm{O}$ unidentate bonds $\left(1680-1720 \mathrm{~cm}^{-1}\right)$ is observed on the delaminated surface spectra, compared to epoxy at initial stage. Thus, there is no doubt that bidentate complexes have been formed preferentially to unidentate complexes. The formation of several types of metal carboxylates with different metal

ions $\left(\mathrm{Na}^{+}, \mathrm{Cu}^{2+}, \ldots\right)$ or coordination mode is apparent from the broad features centered around 1560 and $1420 \mathrm{~cm}^{-1}$.

\section{Conclusion}

Some studies have been lead to understand the cathodic delamination mechanisms of rubber to metal systems. An artificial ageing in laboratory has been compared to ageing in natural conditions in Mediterranean Sea. Both ageings present the same type of degradation which validates the artificial ageing conditions to reproduce the natural conditions. During ageing process, oxygen present in seawater is reduced on the substrate surface submitted to cathodic protection. This reduction reaction produces free radicals which are more destructive than hydroxide ions themselves. After a delay time, this aggressive environment attacks the assemblies at the polymer/metal interface and the delaminated area is proportional to test duration. The delamination is mainly due to an interfacial failure. Consecutively, these radicals also attack the epoxy adhesive and because of the high alkaline environment, several metal carboxylates can be formed. At the delamination front, elastomeric residues which correspond to area more resistant to the oxidative environment are observed. For long immersion time, these residues are also degraded. Different delamination steps could be determined from destructive tests during natural and artificial ageing and from Electrochemical Impedance Spectroscopy.

\section{Acknowledgements}

The authors gratefully acknowledge Thales Underwater Systems for financial support and IFREMER for their contributions. 
1. J.J. Ritter and J. Kruger, Surf. Sci. 96 (1-3) (1980) 364.

2. H. Leidheiser, W. Wang, and L. Igetoft, Prog. Org. Coat. 11 (1) (1983) 19.

3. D. Greenfield and D. Scantlebury, J. Corr. Sci. and Eng. 3 (5) (2000) 1.

4. D.M. Brewis, J. Comyn, A.K. Raval, and A.J. Kinloch, Int. J. Adhes. Adhes. 10 (1990) 247.

5. J.E. Caste and J.F. Watts, Corrosion Control by Organic Coatings. (1981) 78.

6. H.S. Wroblowa, J. Electroanal. Chem. 339 (1-2) (1992) 31-40.

7. E. Koelher, J.F. Watts, and J. Castle, National Association of Corrosion Engineers. 40 (1984)

8. A. Leng, H. Streckel, K. Hofmann, and M. Stratmann, Corros. Sci. 41 (3) (1998) 599.

9. M. Stratmann, R. Feser, and A. Leng, Electrochim. Acta 39 (8-9) (1994) 1207.

10. F. Maile, T. Schauer, et al., Prog. Org. Coat. 38 (2000) 117.

11. A. Leng, H. Streckel, and M. Stratmann, Corros. Sci. 41 (3) (1998) 547.

12. J.E. Castle and J.F. Watts, Ind. Eng. Chem. Prod. R\&D 24 (1985) 361.

13. A. Stevenson, Int. J. Adhes. Adhes. 5 (2) (1985) 81.

14. F.J. Boerio and S.G. Hong, J. Adhes. 30 (1989) 119.

15. S. Touzain, Q.L. Thu, and G. Bonnet, Prog. Org. Coat. 52 (4) (2005) 311.

16. G.P. Bierwagen, L. He, J. Li, L. Ellingson, and D.E. Tallman, Prog. Org. Coat. 39 (2000) 67.

17. A. Miszczyk and K. Darowicki, Corros. Sci. 40 (4-5) (2001) 1337.

18. L. Valentinelli, J. Vogelsang, H. Ochs, and L. Fedrizzi, Prog. Org. Coat. 45 (2002) 405.

19. J.F. Watts, J.M. Atkinson, R.D. Granata, H. Leidheiser, and McBride, J. Adhes. Sci. Technol. 31 (1989) 73.

20. J.F. Watts and J.E. Castle, J. Mater. Sci.18 (10) (1984) 2987.

21. N.J. Harrick, Internal Reflexion Spectroscopy, Wiley, New York (1967).

22. J.F. Watts and J.E. Castle, Proceedings of the International Gas Research Conference, London, UK. June 13-16 (1983) 262.

23. T. Nguyen and J.W. Martin, Durability Build. Mat. 7 (51) (1996) 491.

24. D. Alsheh, T. Nguyen, and J.W. Martin, "Adhesion of Fusion-Bonded Epoxy Coating on Steel in Alkaline Solution," Proc. Adhesion Society Meeting (1994) 209

25. J.L Luo, C.J Lin, Q Yang, S.W Guan, Prog. Org. Coat. 31 (4) (1997) 289

26. V. Feliu, S. Feliu, J. Electroanal. Chem. 435 (1997) 1

27. C. H. Tsai, F. Mansfeld, Corros. Sci. 48 (1993) 726

28. F. Deflorian, L. Fedrizzi, P. L. Bonora, Electrochim. Acta. 38 (1993) 1609

29. H.L. Dinsmore and D.C. Smith, Anal. Chem. 20 (1948) 11.

30. R.C. Mehrotra and R. Bohra, Metal Carboxylates, Academic press, London (1983)

31. J. Catterick and P. Thornton, Adv. Inorg. Chem. Radiochem. 20 (1977) 291.

32. N. Rasoldier, X. Colin, J. Verdu, M. Bocquet, L. Olivier, L. Chocinski-Arnault, and M.-C. Lafarie-Frenot, Compos. Part A 39 (9) (2008) 1522.

33. N. Longieras, M. Sebban, P. Palmas, A. Rivaton, and J.L. Gardette, Polym. Degrad. Stab. 92 (2007) 2190. 
Table 1: analysis of the delamination kinetics for natural and artificial ageing

\begin{tabular}{|c|c|c|}
\hline stage & Artificial ageing $\left.\mathbf{( - \mathbf { 0 . 8 }} \mathbf{V}_{\text {/SCE }}\right)$ & Natural ageing $\mathbf{( - 1 \mathbf { V } _ { \text { /SCE } } )}$ \\
\hline I & $<3$ days & $<15$ days \\
\hline II & $4-15$ days & $15-55$ days \\
\hline III & $11-40$ days & $50-150$ days \\
\hline & $5.5 \mathrm{~mm}^{2} /$ day & $1.3 \mathrm{~mm}^{2} /$ day \\
\cline { 2 - 3 } & $>40$ days & $>150$ days \\
\hline
\end{tabular}




\section{Figures}

Figure 1. Artificial ageing test protocol

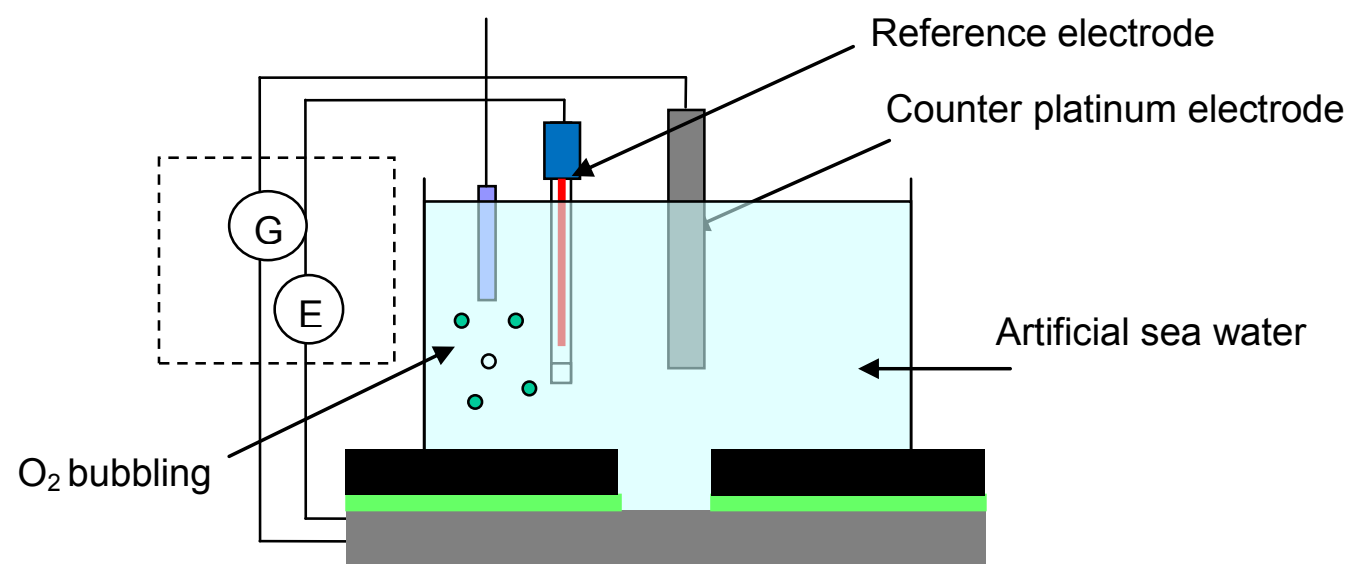

Figure 2. Typical photographs of sample after manual removal a) substrate side, b) rubber side

a)

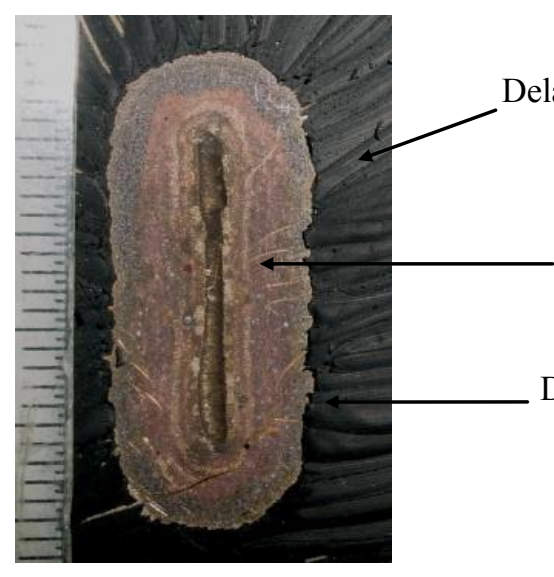

b)

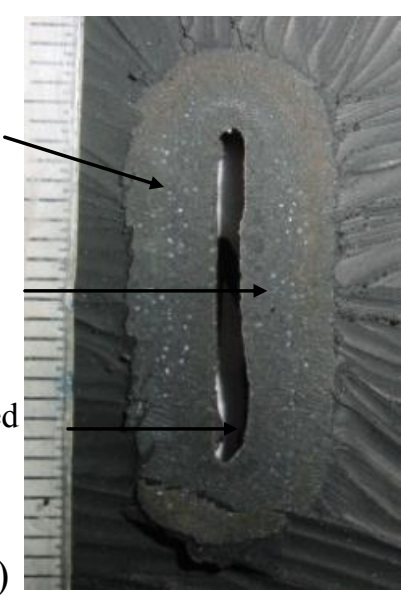


Figure 3. Photographs of samples after a) 3 days of artificial ageing, b) 28 days of artificial ageing c) 58 days of artificial ageing, d) 15 days of natural ageing e) 3 months of natural ageing and f) 6 months of natural ageing.

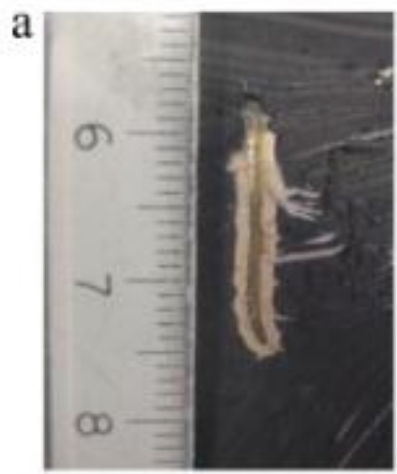

b
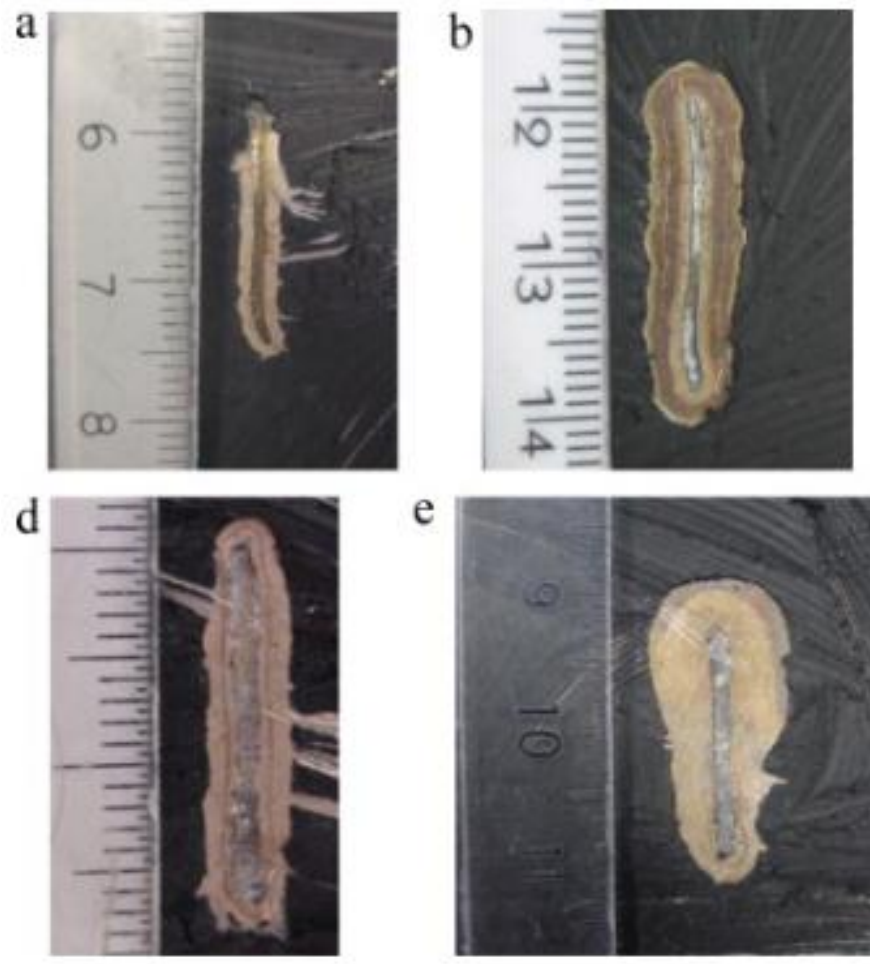

$\mathrm{e}$

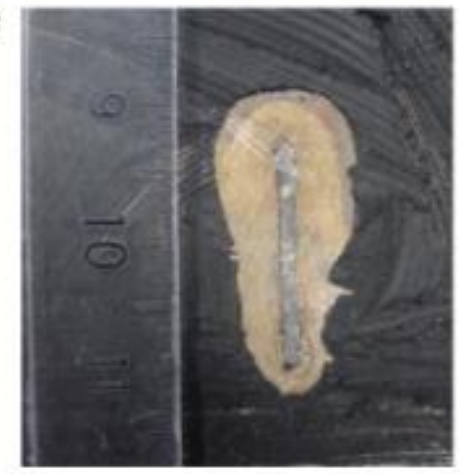

c

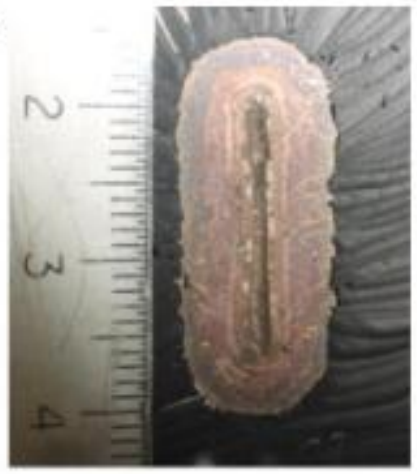

f

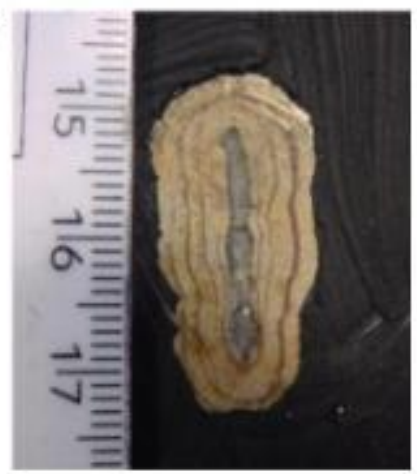

Figure 4. Evolution of delaminated areas with ageing time for natural ageing conditions with the four different stages. The dashed lines define the linear stage III where the delamination rate is calculated (strictly limited to experimental data)

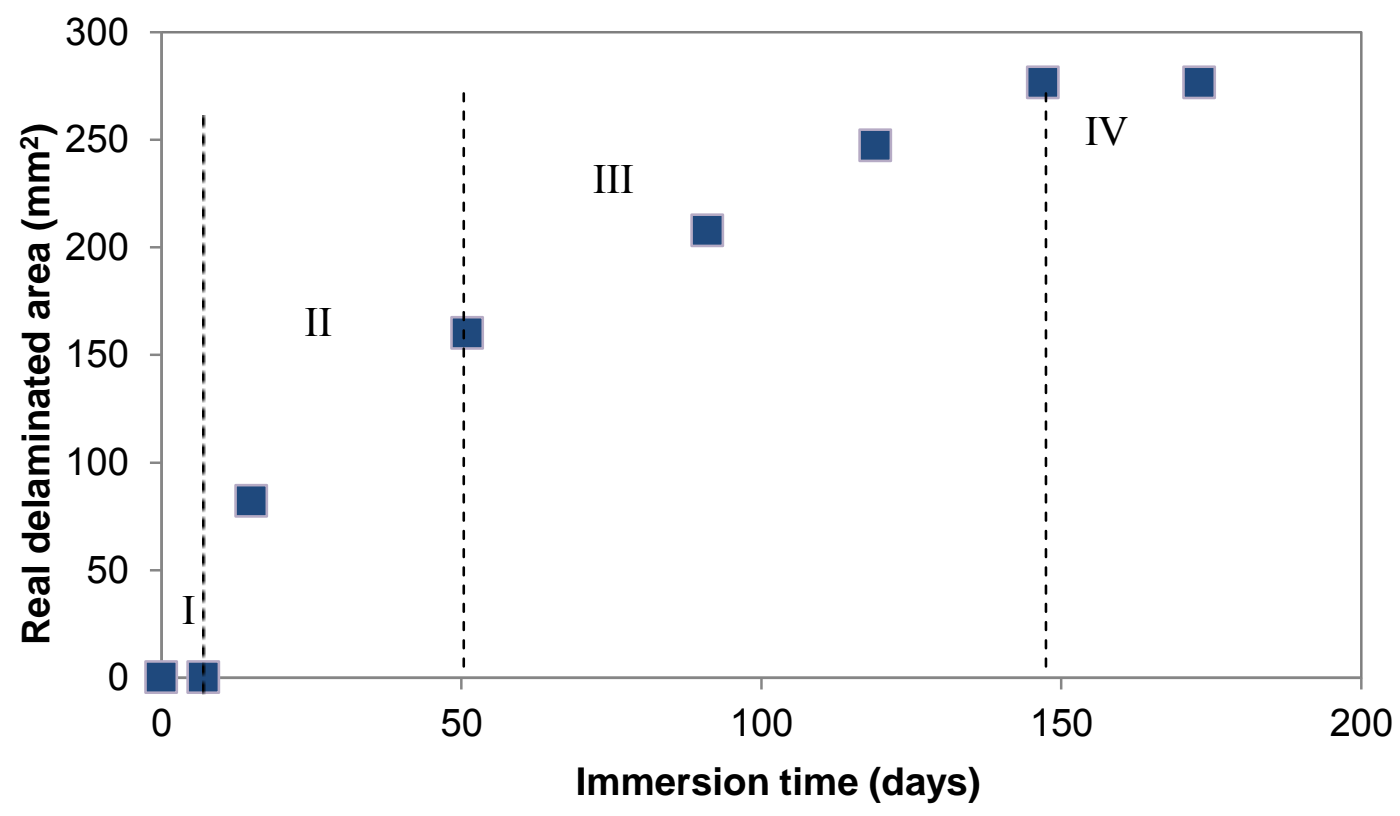


Figure 5. Evolution of delaminated areas for accelerated ageing conditions (-0.8V/SCE) with the four different stages observed in both cases. The dashed lines define the linear stage III where the delamination rate is calculated (strictly limited to experimental data). A good agreement between EIS data (1/Rct) and delaminated areas is observed

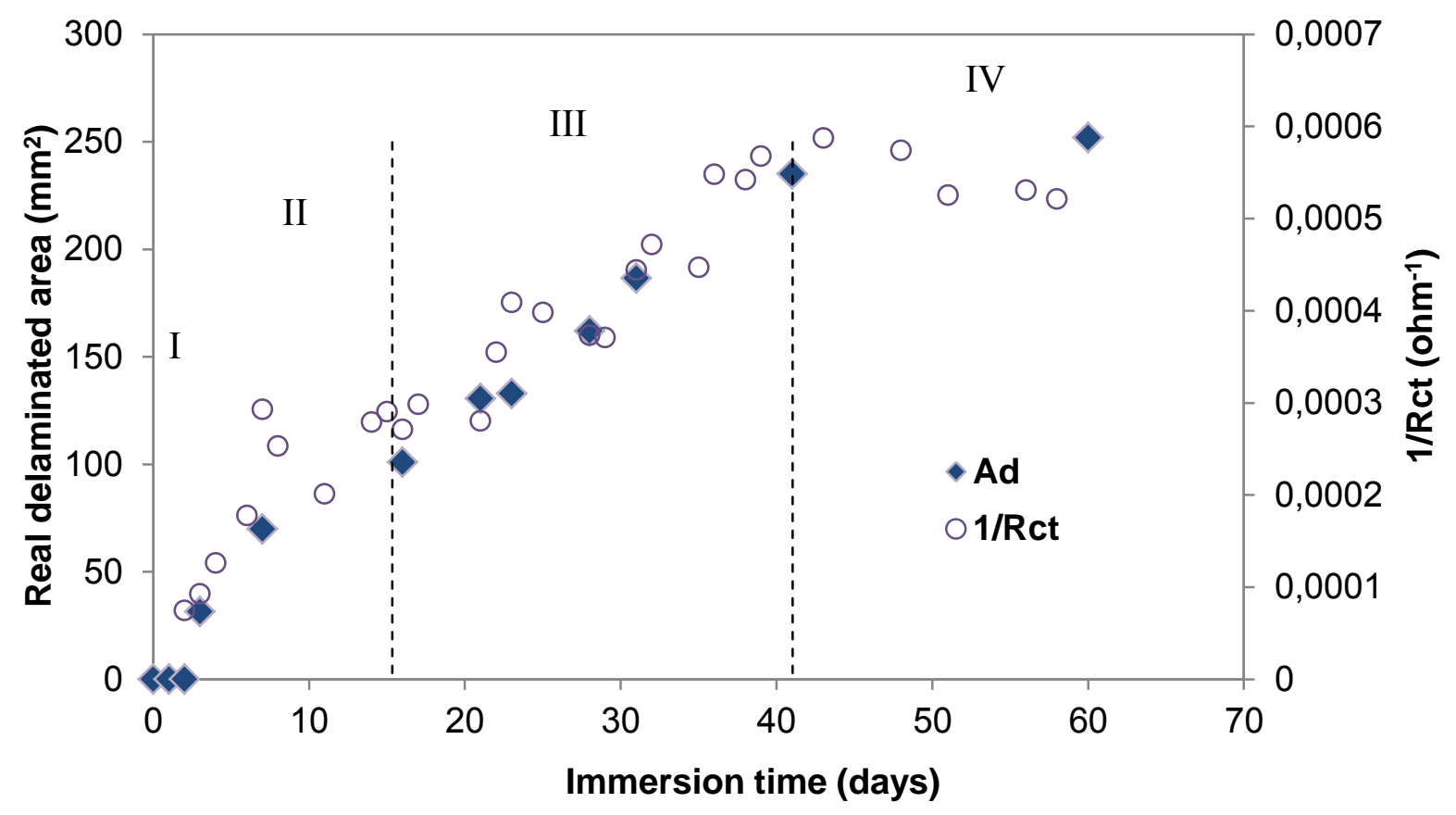


Figure 6. Typical EIS data in Nyquist plot at 28 days of artificial ageing with the Equivalent Electric Circuit used to fit electrochemical response shown as inset

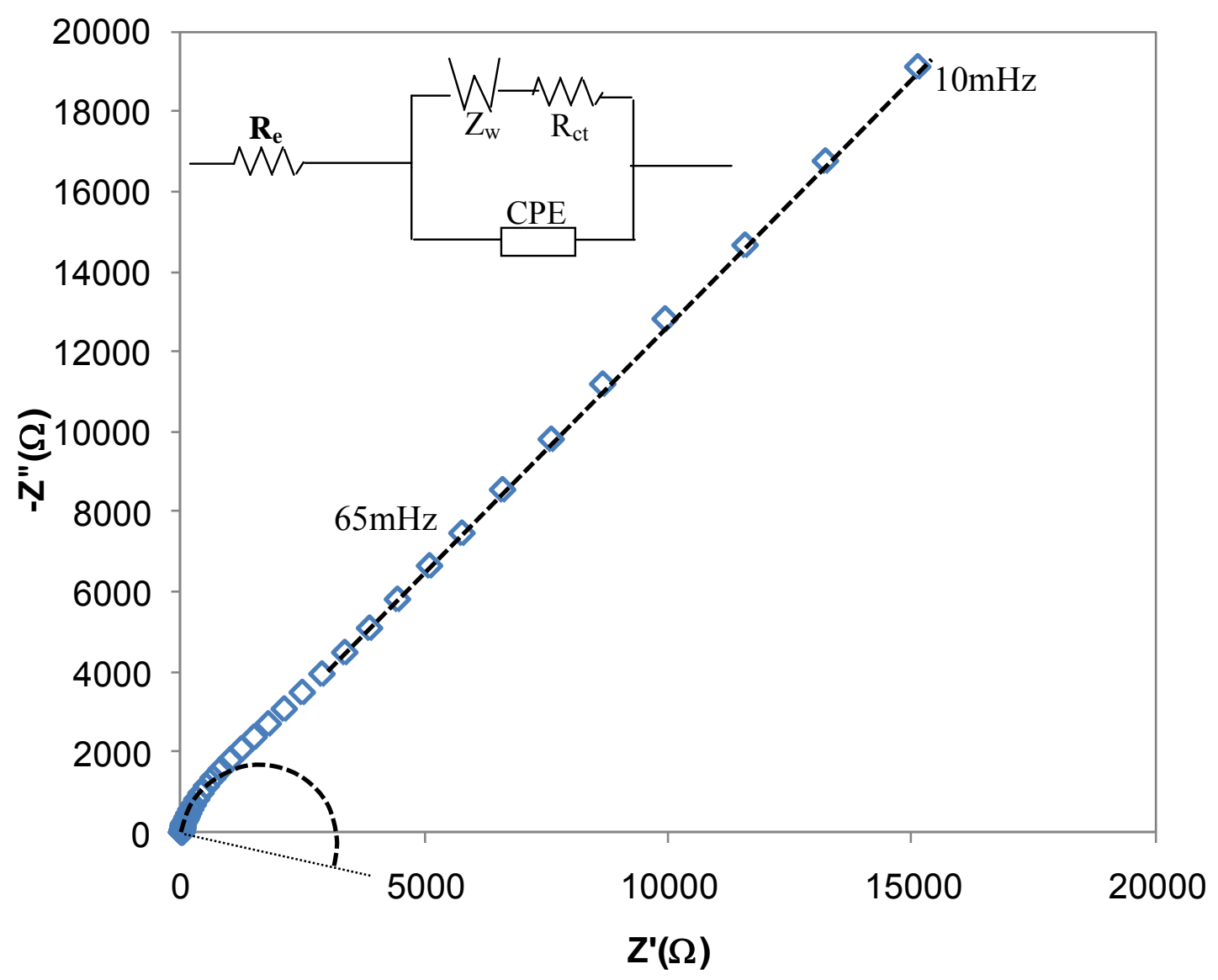


Figure 7. SEM observation of substrate after a) 7 days and b) 58 days of artificial ageing and c) EDX analysis of the black stained areas observed on the substrate after 58 days ofartificial ageing

a)

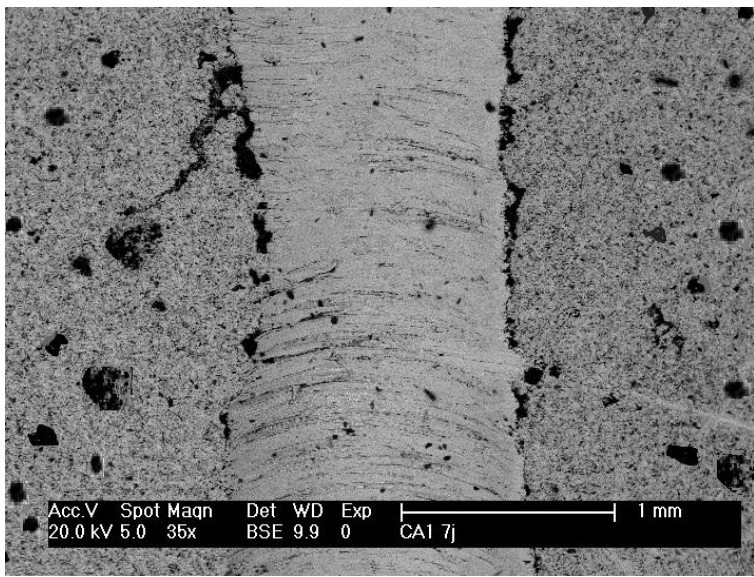

b)

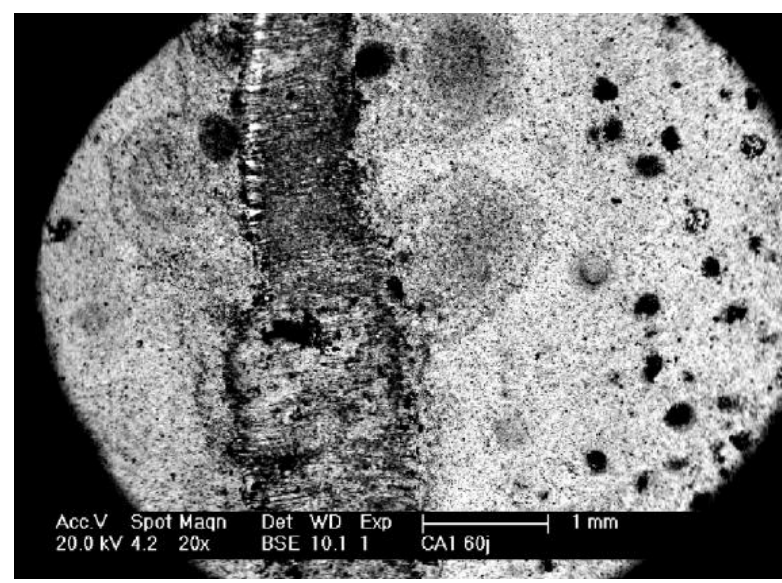

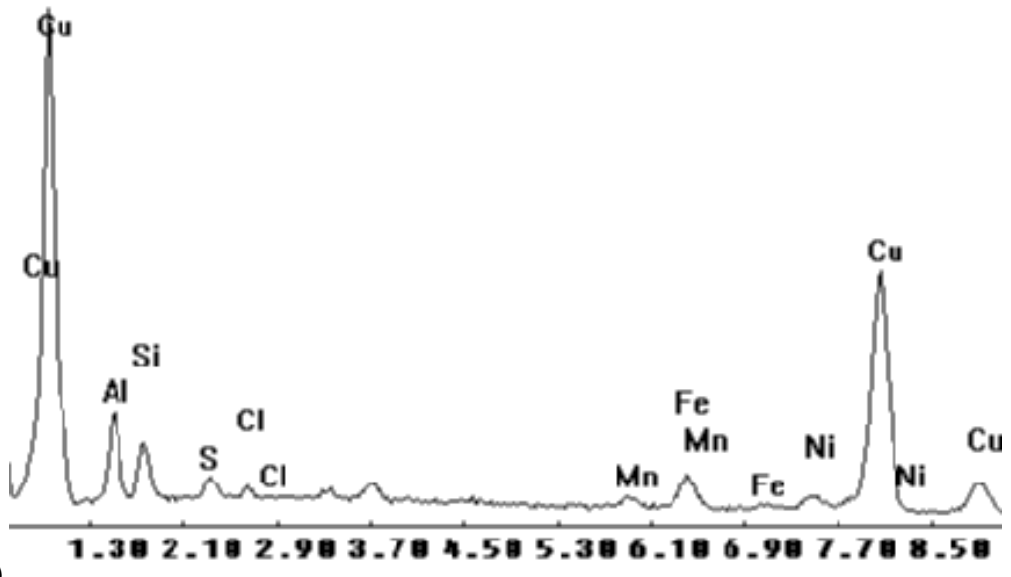

c)

Figure 8. EDX analysis of delaminated surface of elastomer after a) 28 days of artificial ageing and $b$ ) six months of natural ageing
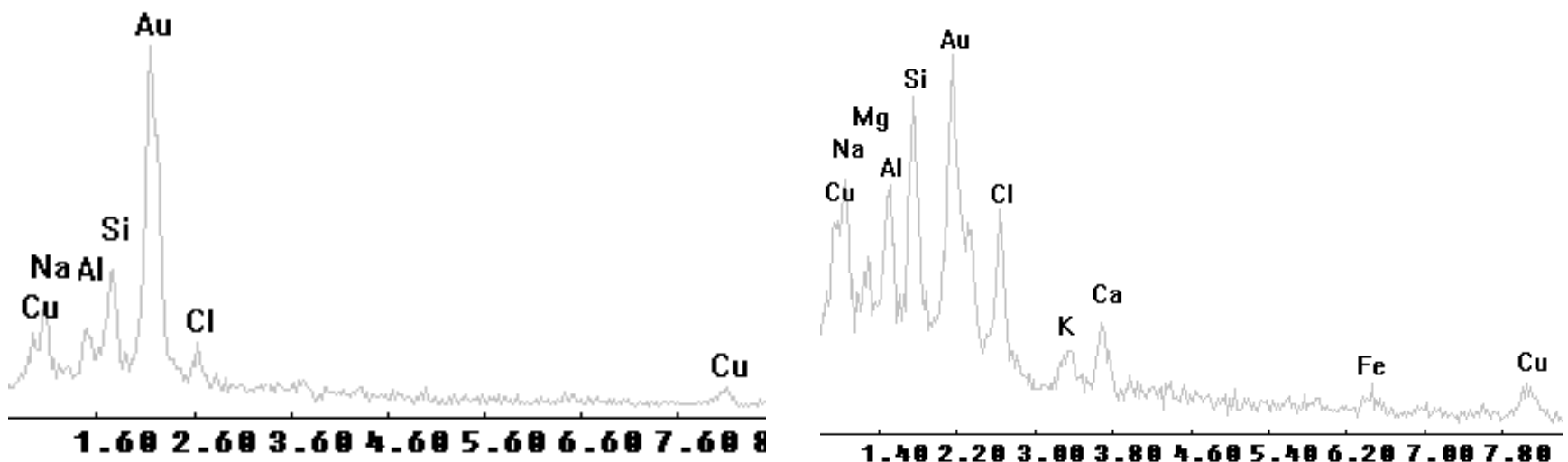

a)

b) 
Figure 9. FTIR spectra of (a) the epoxy adhesive at initial stage, (b) the delaminated surface on polymer side after 28 days of artificial ageing for the polychloroprene/epoxy assembly and (c) the polychloroprene rubber

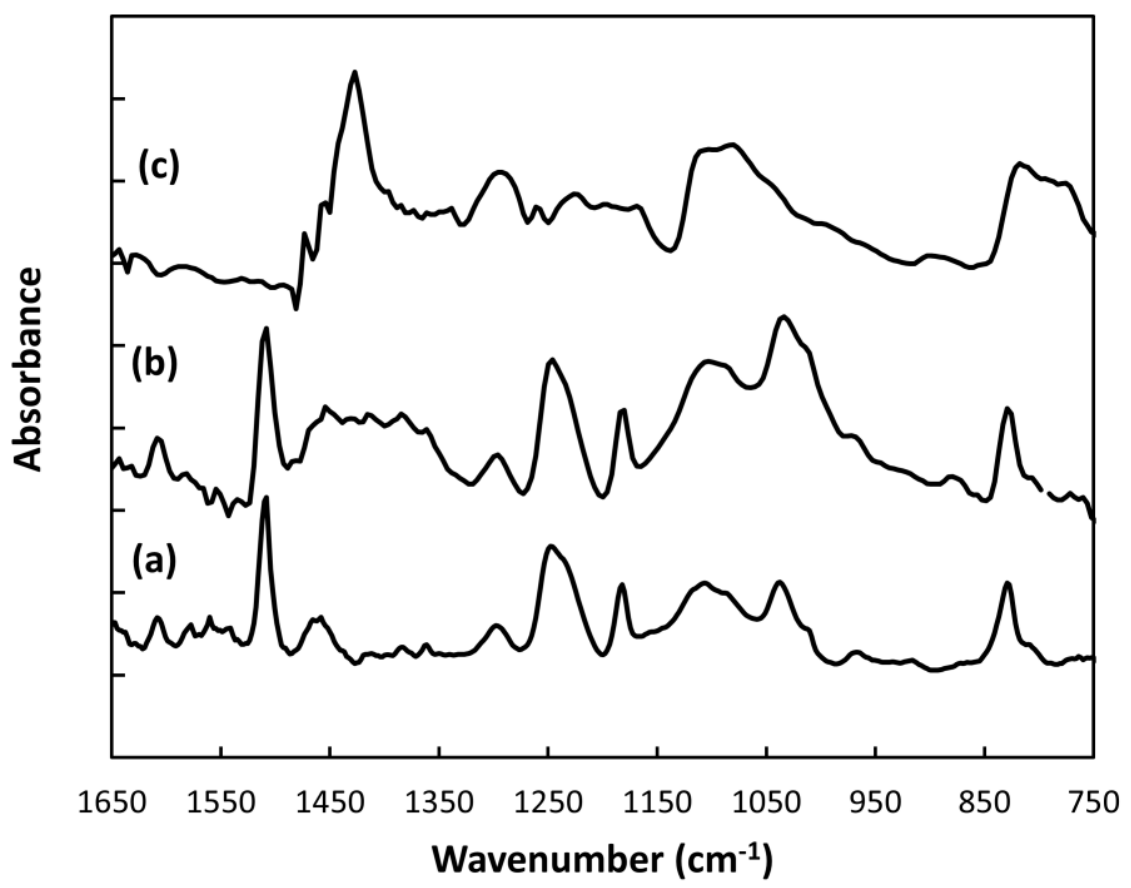

Figure 10. FTIR spectra of (a) the epoxy adhesive at initial stage and (b) to (e) the delaminated surface on polymer side for the polychloroprene/epoxy assembly after (b) 6 months of natural aging and (c) 28 days, (d) 40 days and (e) 58 days of artificial ageing. The two dashed lines are drawn to highlight the increase in the absorption around $1560 \mathrm{~cm}^{-1}$ and $1420 \mathrm{~cm}^{-1}$

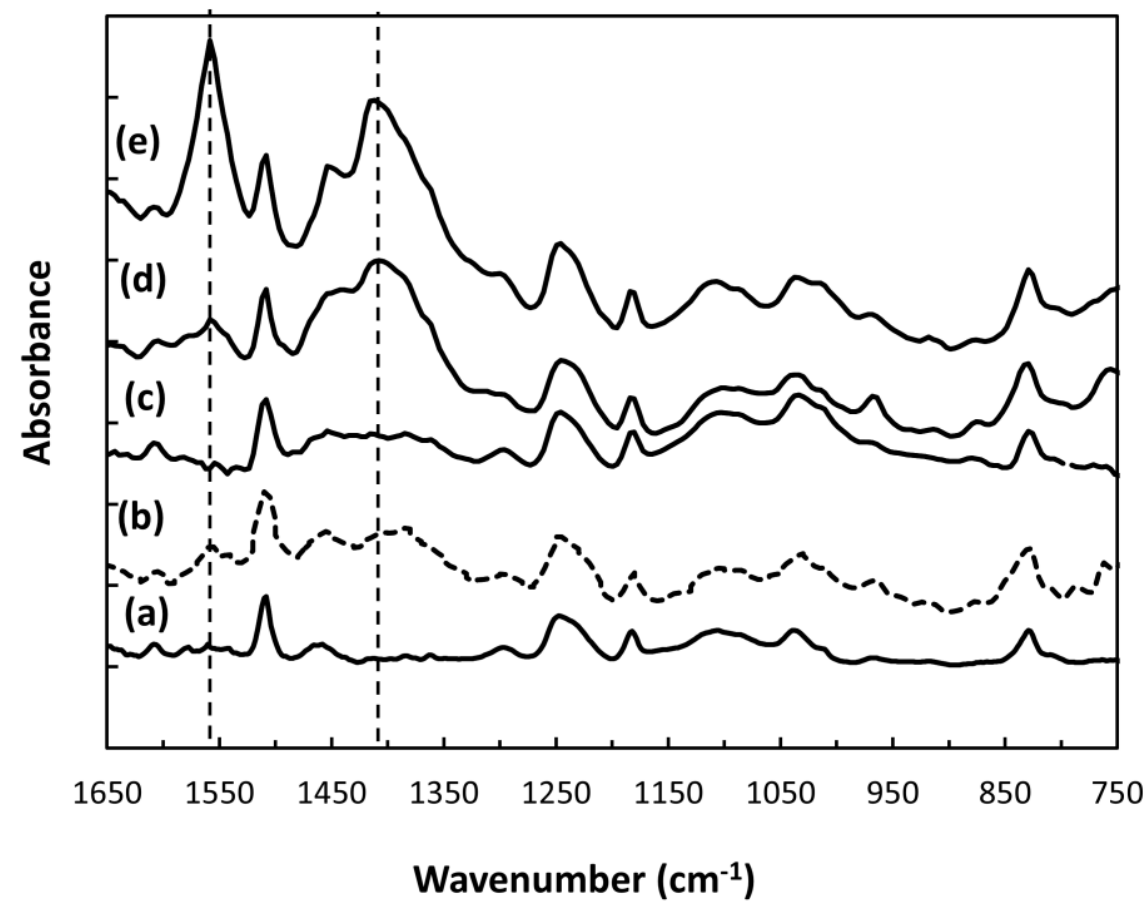


Figure 11. Evolution of the relative peak intensities at $1560 \mathrm{~cm}^{-1}$ and $1415 \mathrm{~cm}^{-1}$ during natural ageing (NAT) and artificial ageing (-0.8V/SCE) (ART) from FTIR analysis of the delaminated surface on polymer side

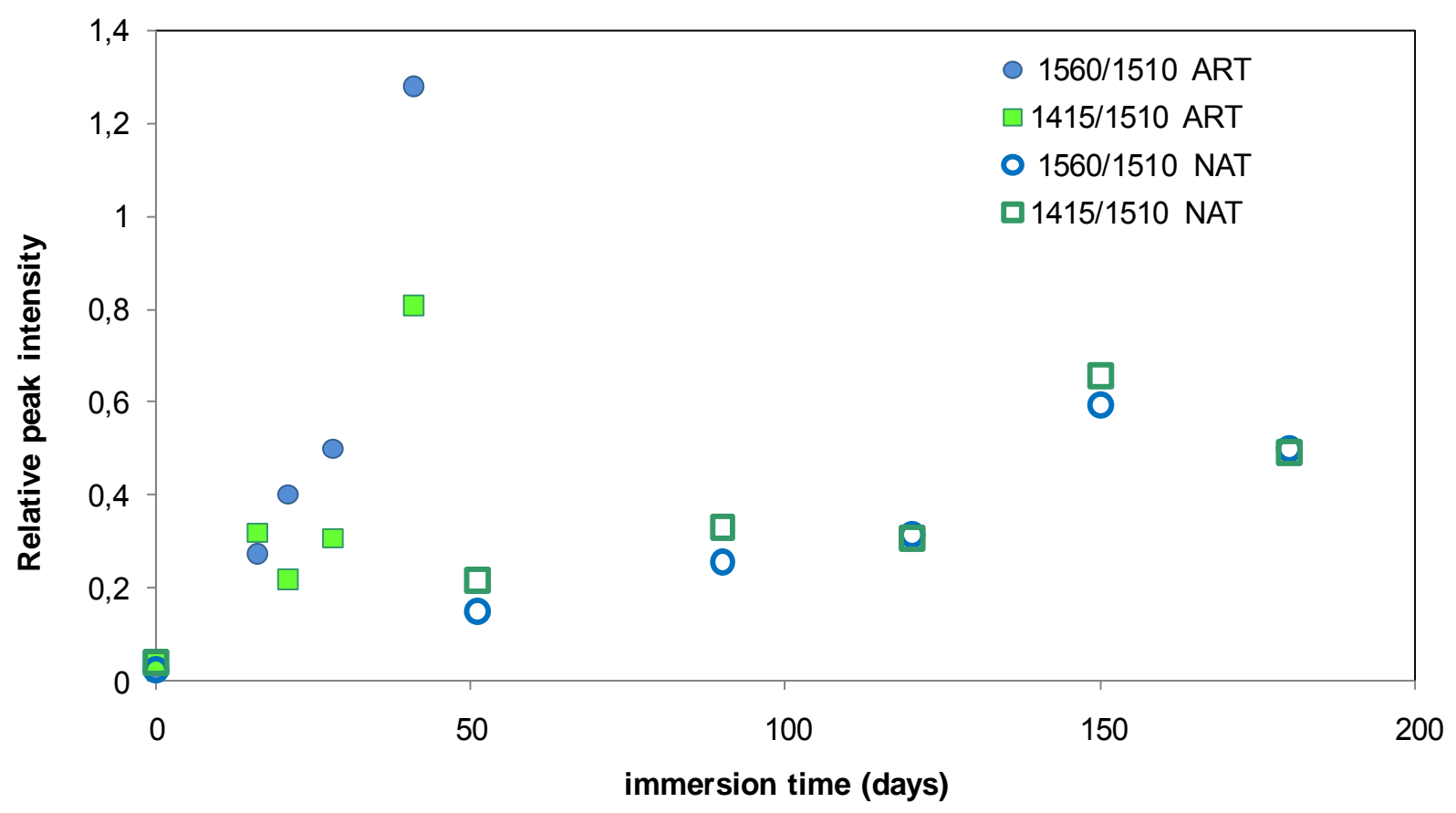

Figure 12. FTIR spectra of (a) the epoxy adhesive at initial stage and (b) the delaminated surface on polymer side after 28 days of artificial ageing for the polyurethane/epoxy assembly. The two dashed lines are drawn to highlight the increase in the absorption around $1560 \mathrm{~cm}^{-1}$ and $1420 \mathrm{~cm}^{-1}$

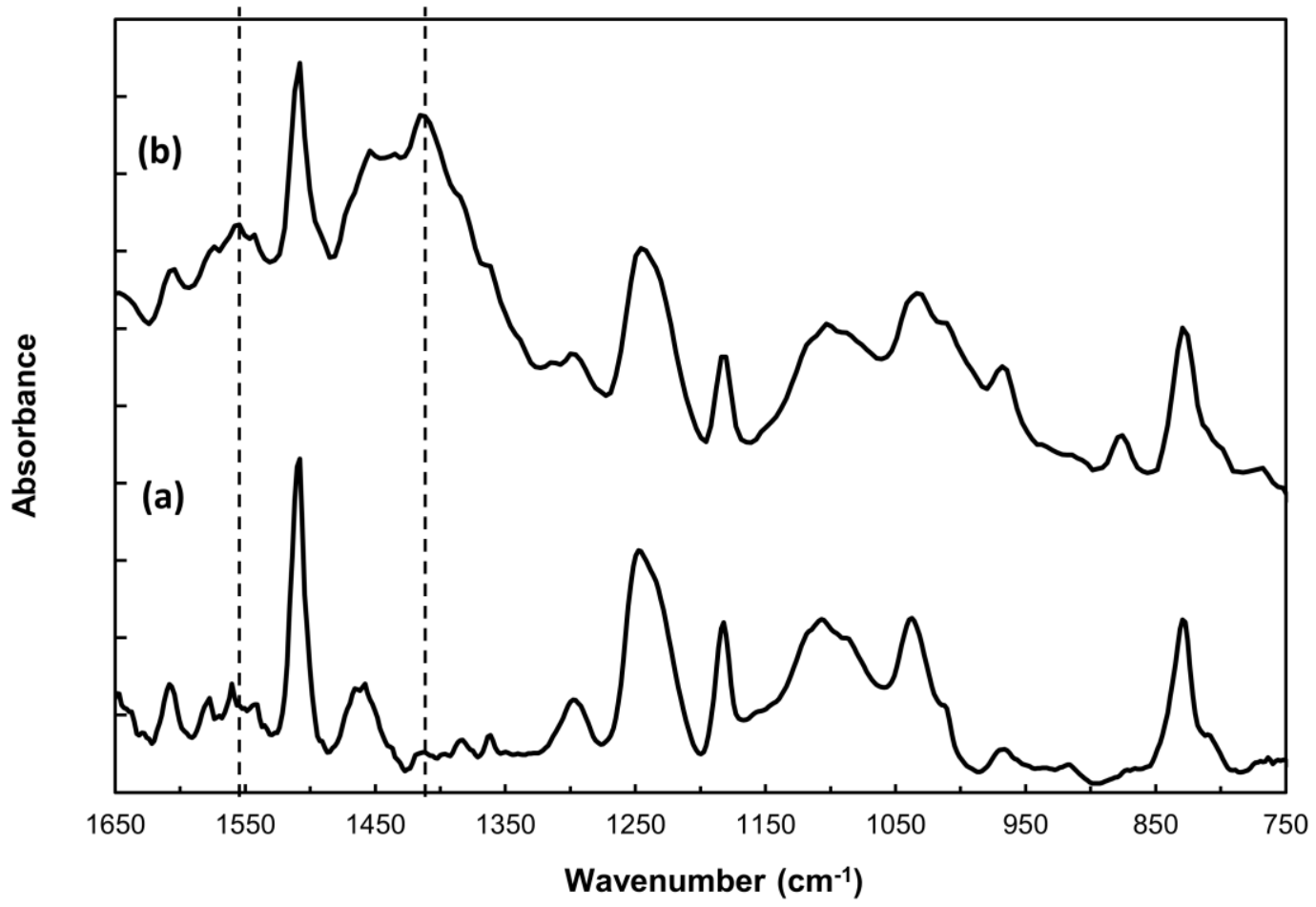


Figure 13. Influence of the cathodic potential on the evolution of the relative peak intensity at $1560 \mathrm{~cm}^{-1}$ during artificial ageing from FTIR analysis of the delaminated surface on polymer side

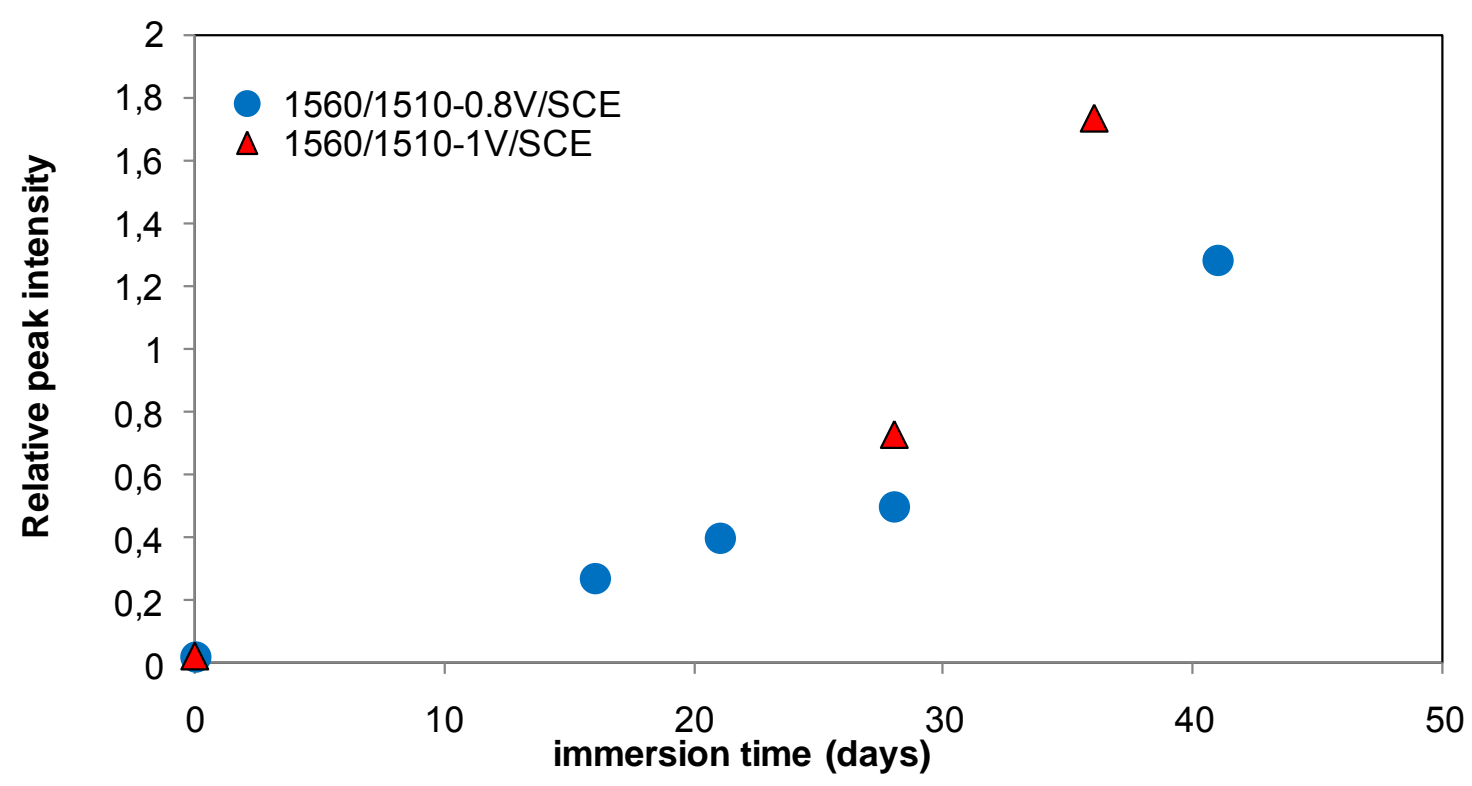

Figure 14. Simplified mechanisms proposed to account for the formation of carboxylic acids chain ends [33]<smiles>COCC(C)O</smiles>

\section{$-\mathrm{H} \bullet$}

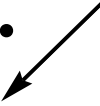<smiles>CC(=O)OP</smiles><smiles>[10BH][10BH]C(C)(O)COC</smiles><smiles>C1=C[Se][Se][Se][As]1</smiles><smiles>CCC(=O)O</smiles>
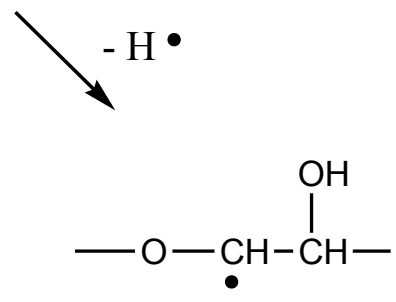<smiles>CC(C)OP</smiles><smiles>COC(O)C(C)O</smiles><smiles>[C]=C</smiles><smiles>CC(O)C(=O)O</smiles> 
Figure 15. Nature of the carboxylate bonding $\left(\mathrm{M}=\mathrm{Na}^{+}, \mathrm{Al}^{3+}, \mathrm{Cu}^{2+}\right)(\mathrm{a})$ unidentate, (b) bidentate chelating, (c) bidentate bridging [30]

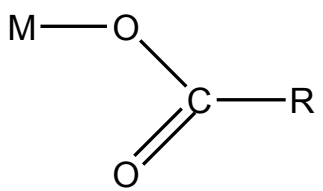

(a)

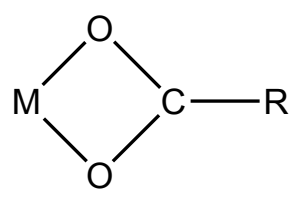

(b)

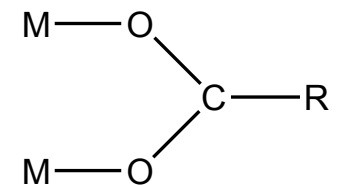

(c) 